\title{
Professional Development in Arts Education for Early Childhood Education: A Creative Exchange Model
}

\author{
Nóirín Hayes $^{1} \mathbb{D} \cdot$ Jacqueline Maguire ${ }^{1}$ (D) $\cdot$ Carmel O'Sullivan $^{1}$ (D)
}

Accepted: 14 June 2021 / Published online: 25 June 2021

(C) The Author(s) 2021

\begin{abstract}
This paper reports a model for professional development for early childhood arts education. The research delivered a co-mentoring programme between early years teachers and artists, which applied a process of 'creative exchange', in which across a period of 2 years, 12 educators and two teaching artists participated. Common principles underpinning early childhood education and arts education include recognition of the critical role of early experiences and relationships and quality learning opportunities as foundations for positive child development. Using these common principles, early childhood educators and artists worked together as equals to provide an enriched early learning environment with improved use of space and materials in an atmosphere of "unhurried time". Themes in the evaluation of the professional outcomes for educators and artists included increased engagement with the arts; changes in pedagogy; building relationships between artists and educators; and the importance of making time for reflection and planning. The creative exchange process led to positive changes in practice and strengthened understandings, for both educators and artists, of the capabilities of young children.
\end{abstract}

Keywords Professional development · Early childhood education · Arts education · Creative exchange $\cdot$ Critical realism

\section{Résumé}

Cet article présente un modèle de perfectionnement professionnel en éducation artistique des jeunes enfants. La recherche offrait un programme de mentorat conjoint entre enseignants de la petite enfance et artistes, avec mise en œuvre d'un processus «d'échange créatif » auquel participaient 12 éducateurs et deux artistes enseignants sur une période de deux ans. Les principes communs qui sous-tendent l'éducation de la petite enfance et l'éducation artistique comprennent la reconnaissance du rôle essentiel des expériences et des relations en bas âge et des occasions d'apprentissage de qualité comme fondements du développement positif de l'enfant. Sur la base de

Nóirín Hayes

nohayes@tcd.ie

1 School of Education, Trinity College, University of Dublin, Dublin, Ireland 
ces principes communs, les éducateurs de la petite enfance et les artistes ont travaillé ensemble sur un pied d'égalité afin d'offrir un environnement d'apprentissage enrichi grâce à une meilleure utilisation de l'espace et des matériaux dans une atmosphère de « temps tranquille ». À l'évaluation des résultats professionnels chez les éducateurs et les artistes, quatre thèmes ont émergé des données : un engagement accru vis-àvis des arts; des changements dans la pédagogie, l'établissement de relations entre artistes et éducateurs, ainsi que l'importance de prendre du temps pour réfléchir et planifier. Le processus d'échange créatif a conduit à des changements positifs de pratique et a renforcé la compréhension des capacités des jeunes enfants, tant chez les éducateurs que chez les artistes.

\section{Resumen}

Este estudio informa sobre un modelo de desarrollo artístico profesional en la educación preescolar. La investigación desarrollo un programa de mentores entre educadores de preescolar y artistas, mediante un proceso de 'intercambio creativo' en el que participaron 12 educadores y dos artistas durante un período de dos años. Los principios comunes en los que se basan la educación preescolar y la educación en artes incluyen el reconocimiento del papel crítico de las experiencias y relaciones tempranas y la calidad de las oportunidades de aprendizaje como base para un desarrollo positivo en la niñez. Utilizando estos principios comunes, los educadores de preescolar y los artistas trabajaron juntos y en la misma medida para brindar un ambiente enriquecido con el uso de espacios y materiales sin presiones de tiempo. La evaluación de los resultados profesionales para educadores y artistas arrojo cuatro temas: aumento de la participación en artes; cambios en la pedagogía; establecimiento de relaciones entre artistas y educadores; e importancia de crear oportunidades para reflexionar y planear. El proceso de intercambio creativo conllevó a cambios positivos en la práctica y fortaleció el entendimiento por parte de educadores y artistas sobre las capacidades de los niños pequeños.

\section{Introduction}

Evidence suggests that the quality of everyday experiences in early childhood environments, including experience of the arts, has a profound influence on children's early learning and development (Dumcius et al., 2014). Based on personal and professional beliefs about children's development, early childhood educators select and provide experiences, which they consider important for positive child development and learning. Increased investment in early childhood education and care in Ireland has led to increased opportunities for professional development programmes for early childhood educators. However, few professional development programmes have focussed on the role of early arts education. This paper reports on the application of a 'creative exchange' process as part of an early arts education professional development project, involving educators. The study aimed to challenge conventional models of professional development in early arts 
education, which typically include an artist in residence who, on conclusion of a short-term project, leaves the setting providing little follow-up.

While the study was conducted in Ireland, its findings have implications for professionals in other countries and cultures where arts education is publicly lauded but frequently relegated to the margins of children's education. Contradictions between early years curriculum frameworks and national arts education policies are common, often resulting in confusion about pedagogical priorities and limited forms of arts practice. The paper discusses a creative exchange process in which 12 educators and 2 teaching artists shared their respective knowledge, skills and expertise to demonstrate that quality arts education is synonymous with quality early childhood education. In this paper, the terms early childhood educator and teacher are used to refer to those working directly with young children in early childhood settings. Both terms are in common usage in Ireland.

\section{Conceptualising Arts Education in ECEC}

A commitment to holistic and integrated practice is shared across early childhood and early arts education with a mutual concern about the over-emphasis on academic learning found in policy documents. Despite the fact that early arts educators and early childhood educators recognise that quality experiences in the arts are critical for young children's development, "arts-based experiences are too often regarded as a supplement to the early childhood curriculum" (Baum, 2017, p.183).

Baum identified two different approaches to arts education in ECEC reflecting the tension between practices that emphasises academic learning skills, particularly in literacy and mathematics for young children, with a view that early childhood is a unique educational stage where relational practice focussing on the affective development of children predominates. This tension serves as a backdrop for two general trends in preparing educators and artists to work with young children: one in which children engage in art activities with a teacher-directed and product-oriented focus, typically identified as craft; the other in which children engage with informed teachers offering unstructured, open-ended opportunities and experiences. Such practice underpins the move away from more traditional curricular approaches to embracing the idea of an emergent curriculum which is responsive to individual children, in which curriculum planning draws on a rich knowledge base and depends on engaged, responsive and attuned early childhood teachers.

Recognising common values between early childhood educators and visual art educators, McClure et al. (2017) specified eight shared principles, which they divided into two categories. Category A principles focus on the child's need for enriched and challenging learning environments providing a wide range of arts materials with sufficient 'unhurried time' to explore, discover and expand learning. In this unhurried time, the child can experience and assimilate the sensory/kinaesthetic properties of materials and develop skills and concepts in re-presenting their experiences. Category B principles focus on the role of adults as 'responsive educators' valuing diversity, supporting development and each child's unique response to the world. A responsive educator is characterised as one who practices a "pedagogy 
of listening' (Rinaldi, 2001), carefully observing and documenting a child's learning to inform quality arts education. The work of McClure et al. (2017) and Baum (2017) informs a framework within which to develop shared scholarship around the potential of arts education in enhancing day-to-day early educational practice and the potential of collaboration in professional development.

\section{Early Arts Education in Ireland}

While noting that little is known about the use of the arts within Irish Early Childhood Education and Care (ECEC) settings, Smyth (2016) points to the importance of access to the arts for young children and identifies the need to ensure that staff are "supported through professional development in this domain" (p. x). Such support has become more critical since the implementation of a two-year entitlement to free preschool for all children over 3 years of age. Stressing the importance of early intervention in providing opportunities for children to express themselves creatively and imaginatively, Smyth (2016) points out that "Patterns of cultural engagement are established from an early age" (p. x). This view has been supported by the Irish Government in ambitious commitments to arts education exemplified by the Arts in Education Charter (Department of Education 2012) and Creative Ireland [2017-2022] (Government of Ireland, 2019) designed to enable the creative potential of every child in Ireland. In an effort to mainstream the value of culture, creativity and arts education in society, Creative Ireland has prioritised ECEC, identifying the provision of professional development for early years teachers as crucial to success.

Both the Charter and Creative Ireland highlight the potential of the Irish early childhood curriculum framework, Aistear (National Council for Curriculum and Assessment [NCCA], 2009), an emergent curriculum built around four themes of Well-Being; Identity and Belonging; Communicating; Exploring and Thinking. Specific attention is given to the objectives under the theme of 'Communicating' aimed at encouraging children to express themselves imaginatively and creatively. Achieving these objectives in arts-based practice requires a particular pedagogical approach which is attained when artists work as part of the early childhood team, trusting the richness of children's ideas, and scaffolding creative environments rather than relying on prescribed or directed learning.

Drawing on analysis of a number of early arts education evaluation studies, Churchill Dower et al. (2013) identify features of successful and sustainable partnerships with artists including shared collaborative approaches and shared professional interests where learning happens for both the artists and early childhood educators. However, they also found that while "... early childhood professionals are doing well in terms of creative skills development with artists, there is a need for artists to be able to access child development knowledge and experience in order to create appropriate practices and approaches" (Churchill Dower et al, 2013; p. 78). On the important issue of collaboration, research highlights the need to look closely at the professional development needs of both artists and educators who are working in partnership in early childhood settings (O'Sullivan \& Rogers, 2018). 


\section{Professional Development in Early Childhood Arts Education}

Professional development and mentoring in early arts education is relatively rare, but a small number of studies have shown positive results from on-site models (Barrett et al., 2019; Mages, 2016). Research consistently finds that high-quality professional development promotes learning that augments the qualifications of those working in ECEC reflecting the correlation between teacher qualification levels and rich learning environments that provide pedagogical stimulation for early childhood provision (Bove et al., 2018). However, qualifications alone are not sufficient: the content, form and characteristics of programmes also matter (Fukkink \& Lont, 2007). In a systematic review of professional development programmes in ECEC, Peeters et al. (2014) identified four features common to effective programmes:

- Active involvement of early childhood teachers;

- Locating the programme within practice;

- Mentoring support is available in staff non-contact time;

- Bedding the programme within a coherent curriculum framework.

Informed by the research on successful professional development programmes, this paper reports on an early arts education programme that was an embedded in the larger Artful Dodgers Project. This was a longitudinal, collaborative study inclusive of programme settings, local government authorities, and academic partners. The first phase of Artful Dodgers (2013) involved an Artist in Residence model where a music artist with a drama background and a visual artist were located together in two early childhood settings on a weekly basis for 12 weeks (Hayes et al., 2017).

Informed by the learning gained in the first phase, the project moved into Phase 2 (2014-2016), and developed, implemented and evaluated a model for 'creative exchange' between educators and artists. It expanded the idea of mentoring to a comentoring mode for enhanced professional learning and the concept of 'creative exchange' formed the basis of this collaborative arts-based programme. Creative exchange is described as a process focussing on the interchange of ideas, to build bridges between individuals and disciplines and support discipline-specific expertise (Fleischmann and Hutchinson, 2012). Reflecting the reciprocal mentoring nature of this phase of the project, creative exchange could be considered as an intersection of the creative arts profession with the early childhood profession and that this process could give rise to new ideas, shared learning, and innovations in both fields and across settings.

The aims for the current study were identified as:

(1) To deliver a co-mentoring programme between the early years teachers and artists where the focus is on 'artistic practice'.

(2) To examine whether Artful Dodgers as an artistic model can sustain arts practices in early years settings.

(3) To critically explore if the model enhances early childhood teachers' knowledge of the arts, initiates a change in their practice, and increases their delivery of the arts in their early childhood settings. 
(4) To review how arts practices in a co-mentoring programme are enabled and supported, and what challenges, if any, are encountered.

\section{Method}

\section{Critical Realism and Arts Research}

Recognising that the world as we know it is constructed from our perceptions and experiences, this study was located within a critical realism paradigm (Fletcher, 2016). Additionally, it was aligned with an arts research framework, which recognised that knowledge alone is insufficient to change practice. Social, cultural, and material contexts in early years settings may impact how change and innovation are received, implemented or sustained (Kontos \& Poland, 2009). As the arts foster creative and critical thinking, build positive relationships, stimulate critical reflection, and nurture empathy (Travis et al., 2020), an arts research framework can facilitate reflection on complex contextual factors which may influence and affect change in our participating early years settings.

In keeping with a critical realism and arts research paradigm (Kontos \& Poland, 2009), participants' narratives and experiences were used to support, challenge or deny existing theories and practices about early arts education. Consequently, and in order to address our research questions, data were drawn from a wide range of sources, including written, audio recorded and photographic records of the arts sessions, and of subsequent dialogic discussions of those experiences by the educators, artists, and researchers.

The research was conducted in accordance with the ethical protocols used by the School of Education, Trinity College Dublin.

\section{Participants}

The programme took place in two community-based early education settings, which had participated in the earlier phase of Artful Dodgers. There were, on average, 50 children aged 3-5 years participating in the study at any one time across the early education settings. Overall, 12 educators and 2 artists participated. It was within these arts-sensitive, early learning environments that opportunities for creative exchange between educators and the artists developed and expanded.

\section{Towards a Model of Creative Exchange}

For the purposes of the study, and in the light of the relationships already formed by the educators and the artists during the earlier Artist in Residence phase of the project, the co-mentoring relationship was one of 'creative exchange' in which the educators planned and led the arts-based sessions with the children, with the active engagement and support from the artists. The project ran over four terms of 
12 weeks, from 2014-2016, with monthly sessions initially in each setting being replaced by a single meeting each term during the later stages of the project.

These critical and collaborative sessions for reflection allowed educators and artists to identify themes and ways of working in, and through, the arts. In addition, annual reviews were held involving the full partnership team of 19 participants, including the educators' managers in each setting, artists, researchers, a local authority arts education officer, and the county childcare committee. These meetings were designed to assess if arts practice had been sustained in each setting, and to consider future directions. At a preparatory meeting, the educators and artists were asked to identify priority areas they wanted to explore, with particular attention placed on how to plan process-based arts sessions, and how to place arts practice at the core of their curriculum.

Each creative exchange session was delivered in the setting and involved a collaborative three-step approach: planning, implementation, and review. Sessions were structured so that educators could begin to work artistically and explore themes through the arts with the children while also having the support of the artists who were present during sessions. Both parties critically reviewed and reflected on their practice after the children had gone home. The creative exchange was evident in this process, when educators and artists had time to examine their practices together, with each contributing from their own areas of expertise to the critical discussion. One artist was funded to provide additional support to each setting outside of the onsite workshops, as needed.

\section{Data Generation and Collection}

Critical reflection and discussions on practice throughout the project were structured using a framework that facilitated an on-going cycle of reflection and evaluation with focused conversations. The project evaluation framework identified four levels of questioning to guide the critical reflection discussions. Known as the ORID framework (Better Evaluation, n.d.), the four levels were:

- Objective (e.g. facts, number of participants, duration of session);

- Reflective (e.g. emotional response to the session);

- Interpretive (i.e. applying meaning to the session, reflecting on personal insights, identifying lessons which could be learned from the session);

- Decisional (i.e. identifying actions/adaptations for the next session).

The implementation of this process involved using 'Post-It' notes and large flip charts which were located around the room on the walls. Artists and educators took $15 \mathrm{~min}$ initially to record their observations and reflections on the notes and flip charts. As well as giving people time to think independently and to ensure that everyone's 'voice' was heard, these notes provided a valuable dataset. Participants placed their notes under each of the organising headings and discussed them as a group. Sessions typically lasted for 1 to $1.5 \mathrm{~h}$ with light refreshments available during that time. One of the artists was also a member of the research team and 
recorded each meeting through a set of detailed minutes, which were then circulated to all members of the research partnership. The artists reflected further on the review process after each meeting, and these data were recorded in written format and also circulated.

Across the 2-year research period, the artists, educators, and researchers also documented the process, including child portfolios of practice. Floor books were created by educators, artists, and children collectively in each setting and documented the creative exchange journey. Floor books are blank books within which to record children's voices, observations, creations, and their ideas, and they act as a site for engaging participants through talking and thinking about learning. They were shared at reflection meetings. Additional data included photographic evidence of arts practice linked to the Aistear curriculum framework, notes, flip-charts and minutes from the creative exchange workshops, partnership meetings, the artists' reflection meetings and transcriptions of the audio recordings from the full partnership review meetings.

The final partnership review was led by the research team and driven by the aims of the study. Using a semi-structured group interview format, data were gathered from the artists, educators, setting managers, a local authority arts education officer and the county childcare committee, addressing what had been learned from the creative exchange process, how it impacted practice, what changes had been made at organisational and practice level in each setting, what challenges had arisen, and what plans, if any, there were for sustaining early childhood arts practice within the settings.

\section{Data Analysis}

Data were analysed using thematic analysis (Braun \& Clarke, 2006). The researchers immersed themselves in the data by listening to recorded interviews and discussions on a number of occasions, reading and re-reading the minutes, using the notes and transcripts, and evaluating visual images, content, and contextual analyses, as proposed by Allen (2017). Exploring the contextual and textual information accompanying the images served to deepen the overall analysis and depth of understanding of the data. Codes and themes were generated from patterns in the data and also from what the researchers identified as information that was surprising or unusual, or other specific differences within, and across, data sets (Creswell, 2013). Following a critical realism arts research paradigm, the research team moved between theory, the empirical results, and the processes and mechanisms of artistic practice which underpinned the project.

\section{Findings}

The analysis of data yielded four central themes which link to the research aims to show evidence about how the project delivered a co-mentoring, creative exchange programme between the early childhood educators and artists. The findings indicated 
that this approach could be a model for sustaining arts practices in early years settings. Furthermore, the findings indicated that the model enhanced early childhood educators' knowledge of the arts and led to changes in practice with increased use of the arts within their settings.

The findings are presented in this section under four themes-Increased Engagement with the Arts; Changes in Pedagogy; Building Relationships between Artists and Educators; Making Time for Reflection and Planning.

\section{Increased Engagement with the Arts}

Data revealed that educators in both settings reported changes in their day-to-day practice with children. As one educator put it, "We got taken out of our comfort zone, which was great.” Another educator explained that:

“... working with the artists promoted an awareness of non-verbal communication ... there was a gesture, an invitation scarf example, a sound, a note, no one was killing each other. It made the staff cut back on the verbal and watch more. Staff are looking and engaging with other forms of communication, for example, their facial expression and their gestures."

All educators reported that they became more confident in trying new things with novel and reusable materials in more flexible ways, noting that their confidence was drawn from the children.

The role of the Irish curriculum framework Aistear in the creative exchange process was commented on by both artists and educators and identified as a powerful context within which to discuss and reflect on arts practice. It was also recognised as helpful in explaining and, where necessary, defending, changes in pedagogical approach to colleagues and parents. This was illustrated in one setting where the Identity \& Belonging theme of the Irish curriculum framework, Aistear was used to elaborate on the following observation:

D's grandfather said that the setting was like a reflection of Africa. The reference here was to the exploratory and messy play that the children were involved in using natural and manmade materials. It was felt that in Ireland children are often deprived of this kind of play, whereas in Africa children play with a full range of natural/environmental materials" (Setting 1 manager).

The idea of working on transitions, slowing things down and paring things back or revisiting a workshop was explored in both settings. This was noted as being highly effective, encouraging artists and educators to become more aware of the importance of giving children "... the time first to just simply explore the materials before other materials, sounds, movements are introduced' (Artist). Both settings reported on the value of realising that "... you could deliver the same session again but do it in a different way" (Educator). Speaking for many of the participants, another educator noted that this was the first time they had experienced this level of sustained professional development for arts education: 
Artful Dodgers has changed how we work ... we're influenced now by the imagination of the child. There was nothing imaginative like this before. There was no going outside the box. We were really only taught like, you know, what would a three-year old be able to do? - not what could you give a three-year old and see what they can do? This is kind of opening up our minds as well.

Sustained engagement with the arts meant that educators' confidence about artistic practices grew over the project period. In following the children's lead, they discovered that they were encountering more authentic forms of artistic engagement.

\section{Changes in Pedagogy}

Moving beyond teacher and artist descriptions of what they did on a day-to-day basis and reports on the challenges faced, the final review explored how the creative exchange process had changed how educators worked. Responses showed a real shift, not only in practice and planning but also in the pedagogical language used by teachers and artists to describe their practice.

In Setting 1, the educators described how they became more child-led in their approach asking children, "What do you want to do?" rather than "We are going to do ...". Educators were clear in their explanations, '... on why we don't use templates anymore' (Manager).

In addition, educators felt more confident that, “... it has changed the why and how we work ... we're not afraid to play" (Educator). Furthermore, they reported increased comfort in talking with parents about their practice and the reasons behind the changes that parents had noticed. One educator clarified that, "Children are going home covered in paints and parents are not complaining, thus reassuring staff that children and parents are both happy". Another described the changes to her practice as, “... A barrier has been broken” (Educator). She was referring not just to the changes in her art practice but to a radically altered perception and understanding of how she now perceived and engaged with the children.

An educator in Setting 2 highlighted changes not only in their use of space but also in their view of space and how to maximise opportunities for extended arts activities to occur. This was a challenge as the setting is small and storage space limited. However, careful planning facilitated more group work and flexible use of time and space. Increased use of music was also reported as changing the overall mood and atmosphere in the setting with the artists reporting that while embedding arts education into everyday practice was a challenge they also saw, “... Art and music seeping into the everyday, over time".

One artist reported that photography as a documentation method was becoming "somewhat invasive" and in conversation with an educator in Setting 2 found a solution through documenting activities by " ... inviting the children to create an image, movement, sound ... that reflects the experience they've had and use that as documentation rather than capturing them doing the actual activity" (Artist). Instead of photographs as records of a visit to a farm, the artist selected children's painting capturing. "... The children's memories of their trip to the farm the day before ..." (Artist). Through this empowering approach, children were facilitated to reflect 
creatively and critically on their experiences using whatever media they wished to use to document their response. In addition, the artists reported a consequent increase in understanding of the capabilities of young children.

The impacts of this creative exchange approach were recorded early in this study, with minutes from an artists' meeting highlighting the value of co-mentoring within this creative exchange process:

Co-mentoring ... is very powerful particularly when it is experiential, and all parties are present (e.g. Early Childhood Teachers and Artists) ... We are all teaching each other. It creates a kind of 'family/shared experience atmosphere', which is very helpful when reviewing pedagogy and practice. It makes it easier to have those conversations and to question, reflect and probe each other. It allows people to stop, think, reflect as a team, plan together and learn from each other.

The study sought to explore if the creative exchange programme initiated a change in educators' practice but did not anticipate the degree to which the artists also reported a shift in their thinking about children's abilities and the pedagogic flexibility required to respond to and meet such needs in ECEC settings.

\section{Building Relationships Between Artists and Educators}

A central factor in incorporating arts-based approaches into practice was the power and quality of the relationships between artists and educators that developed as the project evolved. This was summed up by one educator, as follows:

We did take the time to understand each other, that sustained, informed and nurtured the relationship between the artists, early years teachers, children, parents, funders and researchers... We were all apprehensive at the start, but the art and the children brought us all together as did the space for critical reflection. We reflected after every session together.

For the artists, the relationships were also identified as key, as one artist noted:

Having the full team present has been hugely significant, as everyone is reflecting on practice jointly, sharing learning and observations and coming up with strategies and identifying future thematics/projects to explore with the children based on the children's emerging interests. There is a sense of 'everyone is in this together', and genuine support for each other evident.

The importance of relationships was recognised by the artists as contributing to their learning and these relationships became stronger where, “... There was an open, honest, safe and supportive space to discuss practice" (Artist). While both educators and artists emphasised the importance of relationship the artists also confirmed that they learned new approaches to documenting children's activities gaining increased understanding of child development and learning and the pivotal role that arts education can play in facilitating this in early childhood settings. 
For me the most important thing ... is around relationships and I've worked in residence in lots of different places ... you can be in a very isolated position and I just think that I've learnt the value in not allowing that to happen and allowing for time and space to meet, talk and how much richer the whole experience can be.

Responding to the aims of the study, the data demonstrated that investing time and effort in establishing and maintaining co-equal relationships was central to enabling and sustaining arts practices. However, time was also identified as a challenge.

\section{Making Time for Reflection and Planning}

In response to the question on challenges, educators noted that time for reflection and planning was a concern. However, the ORID framework was identified as a powerful organising structure, which became habitual over the course of the programme and strengthened the experience of reflection impacting positively on planning and pedagogy. Taking shorter moments to 'mull things over' was also noted as helpful, "I take 5 min each day now to reflect" (Educator).

Setting 2 was dealing with staff shortages during part of the programme but reported that "...despite this we did not allow it to stop Artful Dodgers arts activities" (Manager). Setting 1 had to reorganise their routines also, for example, changing lunch times to allow for reflective meetings to occur, and they reported being happy to do so. Sustaining this across the extended period of the project was testament to its value to the educators. In Setting 1 for instance, the full staff team attended the meetings as they wanted everyone to be involved:

“.... [name] who works in the kitchen also attends, as well as the staff from the other ECCE room, which were not involved in Phase one of Artful Dodgers.

Having the full team present has been hugely significant ..." (Artist)

Setting 2 offers full day care, and, as a result, only the two core staff participated in all review sessions, with the other staff attending for shorter periods of time when possible. Consequently, the artists' reflections record that the same level of learning and critical conversations were not happening for the full staff team in Setting 2 as for Setting 1. Despite this, educators in Setting 2 were very clear that reflection time was critical to them in team building and for reflection and planning time.

At the end-of-project review meeting, educators in both settings reported that they had a better understanding of children's development and the power of their active involvement in planning for enriching learning. They also reported an increased awareness of the potential of Aistear and the importance of making time and space for reflection and planning “... it was not just superficial, but instead was a 'double loop', which facilitated reflection and learning ... we examined what we were doing, why and for whose benefit" (Educator). Educators also recognised the role of the artists: "We needed external and professional support. We needed someone to come in from outside ... it wakes up that knowledge in you and gets you to think" (Manager). The educators reported that the creative exchange process. “... broadened our minds, imagination and thinking" while also stressing that the children and staff 
were happier in their everyday activities and willing to try new things, new materials and new ways to think about, and use the setting space.

\section{Discussion}

Staff teams in both settings reported significant changes in their approach to working with young children. The team in Setting 1 showed particular development in their use of pedagogical language, and this shift towards richer pedagogical language is a particularly noteworthy outcome, as previous research has identified that early childhood teachers are, in fact, reluctant to engage in pedagogical discussions or articulate the values, beliefs, and principles underpinning their practice (Stephen, 2010).

The creative exchange process worked to unlock the tacit knowledge of both educators and artists in relation to child development and the role of the arts in ECEC. The quality of relationships and the commitment to giving time to meetings for reflection and planning were identified as critical to the changes reported in both pedagogical understandings and practice. This was further reflected in a shift from teacher-directed, product-oriented activities, towards children engaging and informing teachers' offerings of open-ended opportunities and experiences. A processbased approach was adopted where children were characterised as active agents in their own learning and the pedagogy in both settings moved towards one, which was more child-led. Educators acted as guides and architects of learning through their responsive approach to the opportunities provided by children's own interests and began to think artistically and in the abstract. They explored broad artistic themes such as texture, sound, the sea and the body, and amended access to arts materials, as well as arts provision within their settings. Documentation recorded their process-based arts approach, and noticeboards were created in both settings to record children's emerging interests to be explored through the arts.

The artists too reported a greater understanding of the nature of children's learning and development, which impacted on their engagement with children, particularly in relation to the manner in which they gathered data to inform their planning. Findings also reflect evidence of progress towards alignment of knowledge and beliefs about early learning and the role of the adult, which Baum (2017) argues is necessary in effective professional development. In this study, increased alignment between the educators and the artists provided the foundation for improved practice towards high-quality arts-based early childhood pedagogy.

In meeting the aims of the study, the findings support the shared principles identified by McClure et al. (2017) as common across artists and early childhood educators. This common ground, enhanced by the longitudinal nature of the project, allowed educators and artists to work together as equals towards providing an enriched early learning environment with improved use of space and materials in an atmosphere of 'unhurried time'. The importance of restructuring time and moving from the more rigid routines towards a flexible and responsive practice proved challenging in both settings. However, through opportunities for reflection, discussion and planning, educators did change their practice and both settings reported greater freedom to let go and follow the lead of the children. Importantly the educators grew 
in confidence so that they could explain the changes in their practice to parents who, in both settings, proved very supportive.

Both educators and artists reported that they found new and more effective ways to document children's learning and progress. Not only were changes made to documentation processes, but the changes led to greater engagement with children and a recognition, explicitly on the part of the artists, that inviting children to reflect on their experiences and record them in a variety of different media yielded valuable insights into early learning processes.

The programme was designed to encourage early childhood educators to move away from delivering disjointed/template-based arts activities, and instead reflect on their artistic practice as intentional educators. It functioned as a model of professional development for both artists and educators with its design reflecting best practice through a focus on respectful collaboration between both professions, identifying and responding to shared beliefs and through investing time and energy to allow for reflection, discussion, and planning.

\section{Conclusion and Implications}

This programme enhanced the understanding of the role and potential of arts in early education, led to positive changes in day-to-day practice and strengthened understandings, in both educators and artists, of the capabilities of young children to contribute to their own learning and development. However, the wider landscape within which this study was conducted has to be considered. Posited against a reform culture of 'school readiness', the programme represents an exception rather than the rule. Many countries, including Ireland and the United Kingdom, continue to prioritise mathematics and language development over other areas, with recent reforms to the Early Years Foundation Stage in the United Kingdom predicated on ensuring, “... all children in Reception year leave their crucial first year of school with a better grasp of language, literacy and maths - the building blocks for success later on in life" (Department for Education, 2020). As in Aistear, there is minimal reference to the arts, and where mentioned, the reference is mainly to arts and craft. Arts practice as learning is too often relegated to the margins (Martin et al., 2013), despite evidence that school readiness is best served when children are purposefully and intentionally involved in arts activities, which supports wider educational development (Callcott et al., 2012; McLachlan et al., 2018).

The present study suggests that with appropriate support, educators and managers are receptive to incorporating arts practices as learning into their daily activities. However, we are far away from mainstreaming the experiences represented through this research report. More research is needed to create the compelling case for artistic practices in early childhood education to balance the scales. In the light of the outcomes from this small-scale evaluation programme of creative learning processes and evaluated outcomes, additional research in different countries and in diverse cultures is still needed to support the incorporation of arts education, from the margins to centre stage in early years education. 
Funding Open Access funding provided by the IReL Consortium.

Open Access This article is licensed under a Creative Commons Attribution 4.0 International License, which permits use, sharing, adaptation, distribution and reproduction in any medium or format, as long as you give appropriate credit to the original author(s) and the source, provide a link to the Creative Commons licence, and indicate if changes were made. The images or other third party material in this article are included in the article's Creative Commons licence, unless indicated otherwise in a credit line to the material. If material is not included in the article's Creative Commons licence and your intended use is not permitted by statutory regulation or exceeds the permitted use, you will need to obtain permission directly from the copyright holder. To view a copy of this licence, visit http://creativecommons.org/licen ses/by/4.0/.

\section{References}

Allen, M. (2017). Visual images as data within qualitative research. In M. Allen (Ed.), The Sage encyclopedia of communication research methods. SAGE.

Barrett, M. S., Zhukov, K., \& Welch, G. F. (2019). Strengthening music provision in early childhood education: A collaborative self-development approach to music mentoring for generalist teachers. Music Education Research, 21(5), 529-548.

Baum, A. C. (2017). Powerful allies: Arts educators and early childhood educators joining forces on behalf of young children. Arts Education Policy Review, 118(3), 183-188.

Better Evaluation (n.d.). ORID Evaluation and Facilitation Framework. https://www.betterevaluation. org/en/search/site/ORID\%20framework

Bove, C., Jensen, B., Wyslowska, O., Iannone, R. L., Mantovani, S., \& Karwowska-Struczyk, M. (2018). How does innovative continuous professional development (CPD) operate in the ECEC sector? Insights from a cross-analysis of cases in Denmark, Italy and Poland. European Journal of Education, 53, 34-35. https://doi.org/10.1111/ejed.12262

Braun, V., \& Clarke, V. (2006). Using thematic analysis in psychology. Qualitative Research in Psychology, 3(2), 77-101.

Callcott, D., Miller, J., \& Wilson-Gahan, S. (2012). Health and physical education: Preparing educators for the future. Cambridge University Press.

Churchill Dower, R., Sandbrook, B., \& Fort, S. (2013). Supporting the growth of early childhood arts practice in Ireland - an international view. In Early Childhood Arts: Three Perspectives. Arts Council, Ireland. https://earlyarts.co.uk/research/early-childhood-arts-three-perspectives-2

Creswell, J. (2013). Qualitative inquiry and research design: Choosing among five approaches (3rd ed.). Sage.

Department for Education [DfE] (2020). Statutory framework for the early years foundation stage. EYFS reforms early adopter version. London, UK. https://assets.publishing.service.gov.uk/government/ uploads/system/uploads/attachment_data/file/896810/EYFS_Early_Adopter_Framework.pdf

Department of Education (2012). Arts in Education Charter. Government of Ireland. Retrieved from, https://www.education.ie/en/Publications/ Policy-Reports/Arts-In-Education-Charter.pdf

Dumcius, R., Peeters, J., Hayes, N., Van Landeghem, G., Siarova, H., Peciukonyte, L., Ceneric, I., \& Hulpia, H. (2014). Study on the effective use of early childhood education and care in preventing early school leaving. Luxemburg: Report for the European Commission, DG-EAC.

Fleischmann, K., \& Hutchison, C. (2012). Creative exchange: An evolving model of multidisciplinary collaboration. Journal of Learning Design, 5(1), 23-31.

Fletcher, A. (2016). Applying critical realism in qualitative research: Methodology meets method. International Journal of Social Research Methodology, 20(2), 181-194.

Fukkink, R., \& Lont, A. (2007). Does training matter? A meta-analysis and review of caregiver training studies. Early Childhood Research Quarterly, 22(3), 294-311.

Government of Ireland (2019). Creative youth: A plan to enable the creative potential of every child and young person. Dublin: Government of Ireland. https:/www.creativeireland.gov.ie/app/uploads/ 2019/12/CI_ChildrensPlan_Screen_1.pdf

Hayes, N., Maguire, J., Corcoran, L., \& O’Sullivan, C. (2017). An arts education research project in early childhood settings. Irish Educational Studies, 36(2), 203-219. 
Kontos, P. C., \& Poland, B. D. (2009). Mapping new theoretical and methodological terrain for knowledge translation: Contributions from critical realism and the arts. Implementation Science. https:// doi.org/10.1186/1748-5908-4-1

Mages, W. (2016). Taking inspiration from Reggio Emilia: An analysis of a professional development workshop on fostering authentic art in the early childhood classroom. Journal of Early Childhood Teacher Education, 37(2), 175-185.

Martin, A. J., Mansour, M., Anderson, M., Gibson, R., Liem, G. A. D., \& Sudmalis, D. (2013). The role of arts participation in students' academic and nonacademic outcomes: A longitudinal study of school, home, and community factors. Journal of Educational Psychology, 105(3), 709-727.

McClure, M., Tarr, P., Thompson, C. M., \& Eckhoff, A. (2017). Defining quality in visual art education for young children: Building on the position statement of the early childhood art educators. Arts Education Policy Review., 118(3), 154-163.

McLachlan, C., Fleer, M., \& Edwards, S. (2018). Early childhood curriculum: Planning, assessment and implementation (3rd ed.). Cambridge.

National Council for Curriculum and Assessment. (2009). Aistear: The Early Childhood Curriculum Framework. Dublin: National Council for Curriculum and Assessment.

O'Sullivan, C., \& Rogers, D. (2018). All Heads Together. A ReCreate resource for artists and teachers working in inclusive educational settings with reuse materials. Dublin: ReCreate Ireland. https:// cloudnine.ie/wp-content/uploads/2018/12/All-Heads-Together-A-ReCreate-resource-for-artists-andteachers-1.pdf

Peeters, J., Cameron, C., Lazzari, A., Peleman, B., Budginaite, I., Hauari, H., \& Siarova, H. (2014). Impact of continuous professional development and working conditions of early childhood education and care practitioners on quality staff-child interactions and children's outcomes: A systematic synthesis of research evidence. Belgium VBJK (Centre for Innovation in the Early Years).

Rinaldi, C. (2001). The pedagogy of listening: The listening perspective of Reggio Emilia. Innovations in Early Education, 8(4), 1-4.

Smyth, E. (2016). Arts and cultural participation among children and young people: Insights from the Growing Up in Ireland Study. Economic and Social Research Institute. http://www.artscouncil.ie/ uploadedFiles/Arts-and-cultural-particiption-GUI.pdf

Stephen, C. (2010). Pedagogy: The silent partner in early years learning. Early Years: An International Research Journal, 30(1), 15-28.

Travis, S., Stokes-Casey, J., \& Kin, S. (Eds.). (2020). Arts education in action: Collaborative pedagogies for social justice (common threads). University of Illinois Press.

Publisher's Note Springer Nature remains neutral with regard to jurisdictional claims in published maps and institutional affiliations. 